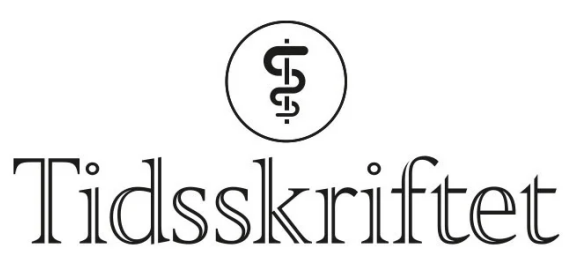

DEN NORSKE LEGEFORENING

\title{
Gul hud uten gulsott
}

MEDISINEN I BILDER

ANDERS BATMAN MJELLE

adnj@helse-bergen.no

Barne- og ungdomsklinikken

Haukeland universitetssjukehus

og

Universitetet i Bergen

Anders Batman Mjelle er overlege og doktorgradsstipendiat.

Forfatteren har fylt ut ICMJE-skjemaet og oppgir ingen interessekonflikter.

\section{HALLVARD MARTIN REIGSTAD}

Barne- og ungdomsklinikken

Haukeland universitetssjukehus

Hallvard Martin Reigstad er seksjonsoverlege.

Forfatteren har fylt ut ICMJE-skjemaet og oppgir ingen interessekonflikter. 


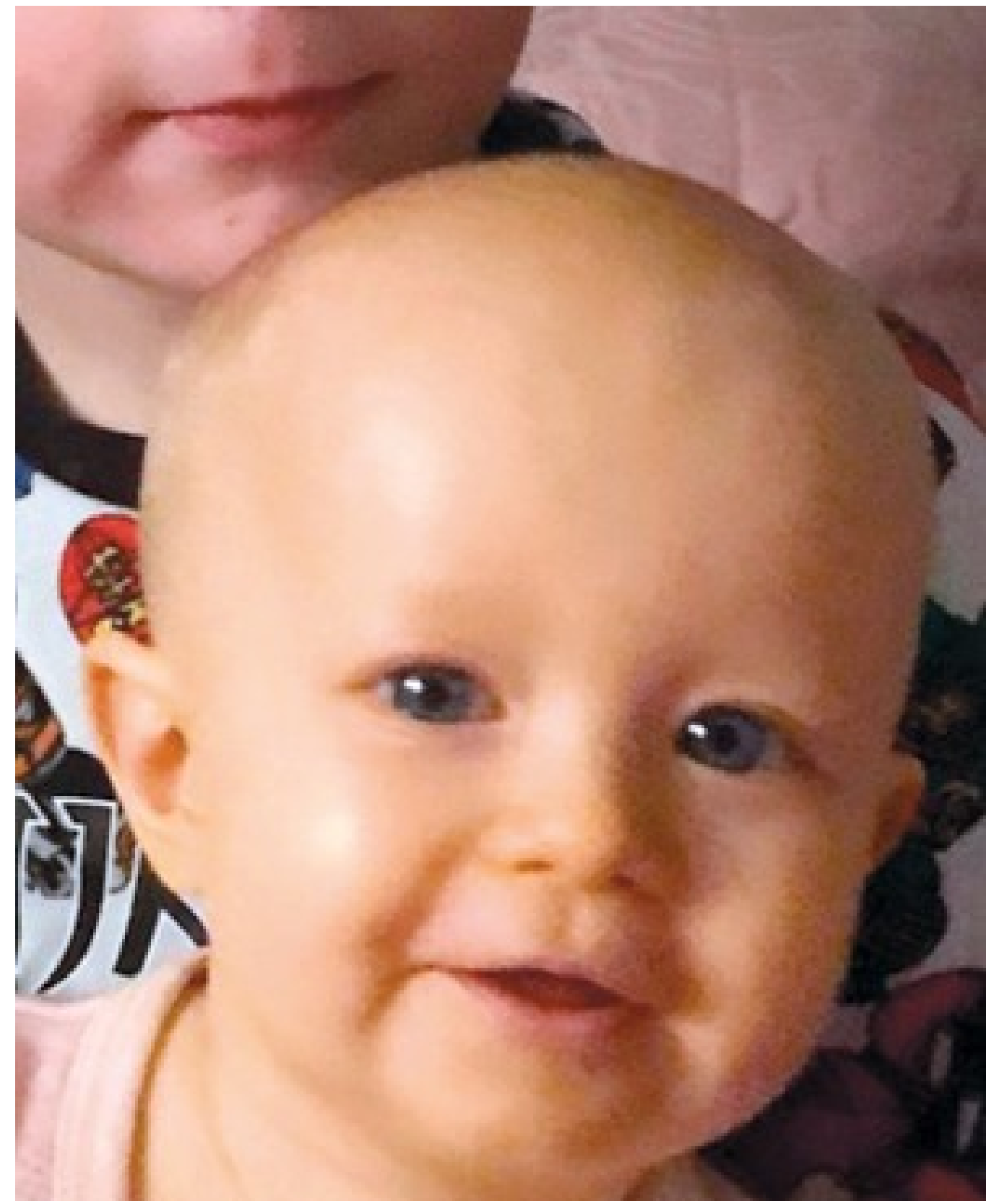

På bildet sees et spedbarn med tydelig gul hud sammen med en slektning med normalt blek hudfarge.

Et tre måneder gammelt barn ble av helsestasjonslege henvist til barneavdeling grunnet gul hudfarge. Barnelegen som så til pasienten, fant et tilsynelatende friskt barn med gul hudfarge og bleke sclerae (bilde). S-bilirubin var $12 \mu \mathrm{mol} / \mathrm{l}$ (referanse $<20 \mu \mathrm{mol} / \mathrm{l}$ ). Barnet ble fullammet, og vektutviklingen hadde vært normal. Avføring og urin hadde normal farge. Konklusjonen var at barnet var friskt, og ingen diagnose ble stilt.

Ved seks måneders alder ble barnet rehenvist av samme helsestasjonslege grunnet fortsatt gul hud. Klinisk undersøkelse, s-bilirubinverdier, øvrige leverprøver, hematologiske parametre, stoffskifteprøver, blodsukker, nyreprøver og vitaminspeil var normale. Barnet ble fortsatt ammet, og ved kostholdsanamnese fremkom det at mor spiste $2 \mathrm{~kg}$ klementiner hver dag. Diagnosen karotenemi ble stilt på klinisk og anamnestisk grunnlag. Ved avsluttende kontroll ved ett års alder hadde mor gradvis sluttet å amme, og barnet hadde nå normal hudfarge.

Karotenoider finnes i frukt og grønnsaker, også grønne grønnsaker, og er viktigste prekursor for vitamin A hos mennesker (1). Karotenemi/karotenoidemi sees spesielt hos spedbarn og småbarn som spiser mye grønnsaker som gulrøtter og søtpotet, særlig pureer av disse, og er også beskrevet ved stoffskiftesykdom, diabetes og leversykdom (1) samt ved 
inntak av karotentilskudd (2). Gulfargen ved karotenemi sees i hud, særlig inni hender, på fotsåler og i nasolabialfurer, men ikke på sclerae eller slimhinner. Det er publisert flere kasuistikker om barn med karotenemi, inkludert spedbarn (3), men vi har bare funnet ett beskrevet tilfelle ved eksklusiv morsmelkernæring (4). I en kasuistikkserie fra den annen verdenskrig beskrives flere kvinner med karotenemi (4.), der hver spiste 1,6-3,2 kg gulrøtter ukentlig. Den ene kvinnen opplevde at hennes diende spedbarn også ble gul i huden, men ikke på sclerae. Begge ble diagnostisert med karotenemi.

Ved reell gulsott har sclerae gul farge, og man skal alltid mistenke leversykdom. Også her er kostholdsanamnese viktig, inkludert kosttilskudd, da dette kan medføre alvorlig leverskade, inkludert fulminant leversvikt (5).

Hudfarge ved karotenemi normaliseres innen 2-6 uker ved diettendring, men det er ingen medisinsk grunn til å endre diett så lenge kostholdet ellers er godt sammensatt (3). Man bør likevel være oppmerksom på muligheten for samtidig vitamin-A-toksisitet, som kan sees ved ekstreme kostholdsvaner (므). Karotenemi og vitamin-A-toksisitet kan oppstå også hos barn med ekstreme og unødvendige eksklusjonsdietter, f.eks. grunnet foreldres redsel for matvareallergi (.7.).

I tilfeller med gult spedbarn skal man i klinisk undersøkelse se på både sclerae og hud. Det viktigste er å utelukke konjugert hyperbilirubinemi, som kan være symptom på gallegangsatresi. Ved denne tilstanden vil barna først få gule sclerae, og de har gulsott utover de to første leveukene. Selv om avfarget avføring er et klassisk tegn på gallegangsatresi, er det på ingen måte obligatorisk. Gult barn over to ukers alder skal derfor vurderes for øyeblikkelig hjelp, uavhengig av farge på avføring.

Pasientens foreldre har samtykket til at artikkelen blir publisert.

Artikkelen er fagfellevurdert.

\section{LITTERATUR}

1. Al Nasser Y, Albugeaey M. Carotenemia. Treasure Island, FL: StatPearls, 2020.

2. Bilimoria S, Keczkes K, Williamson D et al. Hypercarotinaemia in weight watchers. Clin Exp Dermatol 1979; 4:331-5. [PubMed][CrossRef]

3. Leung AKC. Benign carotenemia in children. Can Fam Physician 1989; 35: 81-3. [PubMed]

4. Almond S, Logan RF. Carotinaemia. BMJ 1942; 2: 239-41. [PubMed][CrossRef]

5. Navarro VJ, Barnhart H, Bonkovsky HL et al. Liver injury from herbals and dietary supplements in the U.S. Drug-Induced Liver Injury Network. Hepatology 2014; 60: 1399-408. [PubMed][CrossRef]

6. Nagai K, Hosaka H, Kubo S et al. Vitamin A toxicity secondary to excessive intake of yellow-green vegetables, liver and laver. J Hepatol 1999; 31:142-8. [PubMed][CrossRef]

7. Gangakhedkar A, Somerville R, Jelleyman T. Carotenemia and hepatomegaly in an atopic child on an exclusion diet for a food allergy. Australas J Dermatol 2017; 58: 42-4. [PubMed][CrossRef]

Publisert: 20. august 2020. Tidsskr Nor Legeforen. DOI: 10.4045/tidsskr.19.0667

Mottatt 16.10.2019, første revisjon innsendt 15.4.2020, godkjent 22.4.2020.

(C) Tidsskrift for Den norske legeforening 2023. Lastet ned fra tidsskriftet.no 26. april 2023. 